\title{
Corrigendum: Evaluation of success criteria for temporomandibular joint arthrocentesis
}

\author{
Onur Yilmaz ${ }^{1}$, Celal Candirli ${ }^{1}$, Emre Balaban ${ }^{1}$, Mehmet Demirkol ${ }^{2}$ \\ ${ }^{I}$ Department of Oral and Maxillofacial Surgery, Faculty of Dentistry, Karadeniz Technical University, Trabzon, \\ ${ }^{2}$ Department of Oral and Maxillofacial Surgery, Faculty of Dentistry, Gaziantep University, Gaziantep, Turkey
}

J Korean Assoc Oral Maxillofac Surg 2019;45:15-20 _ https://doi.org/10.5125/jkaoms.2019.45.1.15

This correction is being published to correct the ethical approval number and the treatment interval of patients in above article. The authors apologize for their omission and state that this does not change the scientific conclusions of the article, and regret the inconvenience caused.

\section{Before correction}

\section{Material and Methods}

All patients were treated at the Department of Oral and Maxillofacial Surgery, Faculty of Dentistry, Karadeniz Technical University (Trabzon, Turkey) between 2016 and 2017. This study was conducted in compliance with the principles of the Declaration of Helsinki and with the approval of the Human Ethics Committee of Karadeniz Technical University (2015/78).

\section{Ethics Approval and Consent to Participate}

This study approved by the Human Ethics Committee of Karadeniz Technical University (2015/78). Informed consent was obtained from all individual participants included in this study.

After correction

\section{Materials and Methods}

All patients were treated at the Department of Oral and Maxillofacial Surgery, Faculty of Dentistry, Karadeniz Technical University (Trabzon, Turkey) between January 2015 and 2016 January. This study was conducted in compliance with the principles of the Declaration of Helsinki and with the approval of the Human Ethics Committee of Karadeniz Technical University (2016/8).

\section{Ethics Approval and Consent to Participate}

This study approved by the Human Ethics Committee of Karadeniz Technical University (2016/8). Informed consent was obtained from all individual participants included in this study.

(c) This is an open-access article distributed under the terms of the Creative Commons Attribution Non-Commercial License (http://creativecommons.org/licenses/by-nc/4.0/), which permits unrestricted non-commercial use, distribution, and reproduction in any medium, provided the original work is properly cited.

Copyright (C) 2019 The Korean Association of Oral and Maxillofacial Surgeons. All rights reserved. 